Ano 4, número 7, semestral, setembro 2014

Dossiê /I EBPC 


\title{
Em busca da institucionalização: a adesão ao Sistema Nacional de Cultura
}

\author{
En busca de la institucionalización: adhesión al Sistema Nacional de \\ Cultura
}

\section{In pursuit of institutionalization: accession to the National System of Culture}

Alexandre Barbalho ${ }^{1}$

Palavras chave:

Sistema Nacional de Cultura

Federalismo

Democracia

Participação
Resumo:

A presente reflexão objetiva perceber a receptividade dos governos estaduais e municipais ao Sistema Nacional de Cultura (SNC) implementado pelo Ministério da Cultura. Tal problemática se coloca na medida em que a participação dos entes federados é por adesão e prevê a participação dos mais diversos agentes sociais. Interessa acessar os discursos produzidos por esses agentes com o intuito de estabelecer algumas considerações qualitativas sobre suas participações. Para tanto, analisamos um conjunto de 234 notificações na internet sobre o SNC recolhidas entre 01 de setembro e 23 de novembro de 2013. A partir dos discursos analisados, concluise que houve em torno do SNC um processo de hegemonização, ou seja, de construção de uma ampla identidade social com essa política cultural, tendo o Ministério da Cultura como agente principal na articulação das diferentes posições de sujeito. 


\section{Resumen:}

Esta reflexión objetiva percibir la receptividad de los gobiernos al Sistema Nacional de Cultura (SNC) implementado por el Ministerio de Cultura. Este problema ocurre en la medida que la participación de las entidades federativas es por adhesión e incluye la participación de varios agentes sociales. Interesa acceder a los discursos producidos por estos agentes con el fin de establecer algunas consideraciones cualitativas en sus participaciones. Para eso, analizamos un conjunto de 234 informes en Internet sobre el SNC recogidos entre 01 de septiembre y 23 de noviembre de 2013. Desde los discursos analizados, se concluyó que hubo en torno del SNC un proceso de hegemonización, es decir, la construcción de una amplia identidad social con esa política cultural y el Ministerio de Cultura como el agente principal en la articulación de las diferentes posiciones de sujeto.
Palabras clave:

Sistema Nacional de Cultura

Federalismo

Democracia

Participación

\section{Keywords:}

National Culture System

Federalism

Democracy

Participation

\section{Abstract:}

This reflection aims to understand the responsiveness of state and local governments to the National Culture System (NCS) implemented by the Ministry of Culture. This problem arises in that the participation of federal agencies is by adhesion and provides for the participation of several social agents. Interests to access the discourses produced by these agents in order to establish some qualitative considerations on their participation. To this end, we analyzed a set of 234 reports on the internet about NCS collected between September 1 and November 23, 2013. From the speeches analyzed, it was concluded that there was around the National Culture System a process of hegemony, ie, of constructing a broad social identity with the cultural policy, and the Ministry of Culture as the main agent in the articulation of different subject positions. 


\section{Em busca da institucionalização: a adesão ao Sistema Nacional de Cultura}

\section{Introdução}

A área da cultura como objeto de políticas públicas no Brasil tem sido historicamente relegada a planos secundários, apesar de não ser correto afirmar que tais políticas tenham um caráter tardio, se comparada a outros setores. Pode-se identificar o seu surgimento, no âmbito federal, durante o governo Vargas (1930-1945), momento no qual se estruturam de fato políticas para setores sociais como educação, saúde, seguridade etc. As ações voltadas à cultura se davam, naquele momento, no interior do Ministério da Educação e Saúde Pública, comandado por Gustavo Capanema. É ainda do mesmo período, agora no plano municipal, a criação em 1935 do Departamento de Cultura e Recreação de São Paulo, cujo primeiro diretor foi o intelectual modernista Mário de Andrade.

Contudo, tais ações e instituições sofreram, ao longo das décadas, com as descontinuidades de suas políticas, as restrições financeiras, a deficiência de quadros técnicos, bem como com as relações clientelistas que, se estão presentes em amplos setores do poder público, se fazem mais intensas na cultura, em muito decorrente da fragilidade do campo, o que resulta em maior dependência de seus agentes dos favores provenientes dos gestores governamentais e de seus intermediários.

Tal contexto não se modificou na sua estrutura com a criação pelo presidente Sarney do Ministério da Cultura (MinC) em março de 1985, pois o novo órgão surge descapitalizado politicamente, financeiramente e simbolicamente, o que comprova a alta rotatividade de ministros. Entre o seu ano de criação e o fim do governo Itamar Fran- co, em 1994, foram 8 ministros, sendo que no governo Collor (1990-1992), o MinC foi transformado em uma secretaria que teve, nesse curto espaço de tempo, dois titulares.

A longa gestão de Francisco Weffort como ministro da cultura no período da presidência de Fernando Henrique Cardoso (1995-2002) se possibilitou uma certa estabilidade às ações do governo federal, estas foram marcadas, paradoxalmente, por uma espécie de retirada do poder público posto que grande parte do que foi executado se deu por meio de leis de incentivo à cultura, a Lei Rouanet e a do Audiovisual, que transferem à decisão de quanto e onde investir aos departamentos de marketing ou, na melhor das hipóteses, ao gestor cultural das empresas (BARBALHO; RUBIM, 2007).

Tal contexto modificou-se de forma estrutural com o governo Lula (2003-2010), nas gestões de Gilberto Gil e Juca Ferreira no MinC, e continua em transformação no atual governo Dilma (2011-2014), que teve como ministras Ana de Hollanda e Marta Suplicy. Se a principal forma de financiamento à cultura continua sendo as leis de incentivo, há um esforço por parte do Ministério em institucionalizar as políticas culturais, não apenas no âmbito federal, mas também nos demais níveis da federação. $O$ objetivo é de que se transformem em políticas de Estado e não apenas de governo e não sofram tantas descontinuidades.

Não é o caso aqui de analisar o que foi feito nesse sentido, mas vale à pena enumerar alguns dos procedimentos mais importantes, aqueles que são fundamentais a esse esforço de institucionalização: realização de Conferências Nacionais de Cultura; elaboração do Plano Nacional de Cultura; reativação e redefinição do Conselho Nacional de Política Cultural e criação do Sistema Federal de Cultura (RUBIM, 2011; 2010).

Contudo, o instrumento que se apresenta como fundamental nesse pro- 
cesso é o Sistema Nacional de Cultura (SNC) por sua própria função de, como indica seu nome, estabelecer, em conjunto com a sociedade, um sistema federativo de políticas públicas específico para a cultura. Tal sistema, ao exigir a criação de mecanismos mínimos para o seu funcionamento nos estados e municípios do país (órgão gestor específico, conselho, plano e fundo de cultura), possibilita algum grau de efetividade das políticas culturais que seja independente do governo vigente (BARBALHO; BARROS; CALABRE, 2013).

Este artigo faz parte de uma pesquisa mais ampla sobre o SNC que visa analisar desde os momentos que antecedem sua proposição no interior do MinC no início da gestão Gil até o atual esforço de sua materialização. A presente reflexão traz como questão geradora perceber a receptividade dos governos estaduais e municipais ao processo de construção do referido sistema.

Tal problemática se coloca na medida em que a participação dos entes federados é por adesão e, por sua vez, o documento base do SNC prevê a participação não apenas dos entes governamentais, como também dos mais diversos agentes sociais. É o que se depreende do artigo 216 - A da Constituição Federal, aprovado pela Emenda Constitucional $n^{\circ} 71 / 2012$ : "O Sistema Nacional de Cultura, organizado em regime de colaboração, de forma descentralizada e participativa, institui um processo de gestão e promoção conjunta de políticas públicas de cultura, democráticas e permanentes, pactuadas entre os entes da Federação e a sociedade".

Ora, ao contrário do Sistema Único de Saúde (SUS), que foi construído a partir de um movimento de base, ou seja, da demanda dos agentes ligados à saúde comunitária e pública ${ }^{2}$, o SNC se apresenta, aparentemente, como uma demanda gerada pelo governo federal aos governos estaduais e municipais e à sociedade ${ }^{3}$.
Mesmo que, segundo Roberto Peixe ${ }^{4}$, um dos articuladores do SNC, ele tenha sido pensado pelos militantes culturais de um partido político, o Partido dos Trabalhadores, o que pretensamente lhe conferiria um caráter de conquista do campo cultural e não o de uma espécie de "cidadania regulada", para usar livremente o clássico termo proposto por Wanderley Guilherme dos Santos (1979).

Não é o caso de investigar aqui a procedência ou não da tese de Peixe. $O$ que nos interessa nesse artigo é observar como ocorrem as múltiplas manifestações de engajamentos dos diversos agentes governamentais e sociais nesse momento de intensa adesão ao plano que antecede à realização da III Conferência Nacional de Cultura, que ocorreu entre 27 de novembro e 01 de dezembro de 2013, e cujo tema era, significativamente, "Uma política de estado para a cultura. Desafios do Sistema Nacional de Cultura" (BRASIL, 2013).

Interessa-me, para além dos dados estatísticos disponibilizados pelo MinC que apontam a adesão ao SNC de todos os 26 estados brasileiros e respectivas capitais, além do Distrito Federal, bem como de 2.068 municípios $^{5}$, e ainda a participação de milhares de pessoas nas centenas de conferências estaduais e municipais de cultura realizadas nos meses imediatamente anteriores à Conferência, acessar os discursos produzidos por esses agentes com o intuito de estabelecer algumas considerações qualitativas sobre suas participações.

Por discurso entende-se, junto com Ernesto Laclau e Chantal Mouffe, "a totalidade estruturada resultante da prática articulatória". Esta, por sua vez, configura-se como "toda prática que estabelece uma relação tal entre elementos, que a identidade destes resulta modificada como resultado desta prática" (LACLAU; MOUFFE, 2001, p. 142). 
Para tanto, analisamos um conjunto de 234 notificações na internet sobre o SNC recolhidas entre 01 de setembro de 2013, período inicial da coleta, e 23 de novembro de 2013, dia anterior ao inicio da III Conferência. Para constituir esse acervo, recorri a um instrumento de notificação de um buscador que enviou para meu correio eletrônico toda postagem que possuísse a expressão "Sistema Nacional de Cultura".

\section{O discurso da participação e da democracia}

Na análise do corpus o que sobressai é o consenso em torno da participação e, por consequência, da democracia no que se refere ao atual momento da política cultural, motivado pelo estabelecimento do SNC e a realização das conferências municipais e estaduais. Não há posição contrária a tais critérios (participação e democracia) em qualquer um dos discursos analisados, pois são vistos como fundante para o bom desempenho das políticas culturais em todos os níveis da federação.

Eles são valorados tanto por políticos em cargos executivos e gestores públicos estaduais e municipais, quanto pelos que ocupam cargos no legislativo (deputados e vereadores), inclusive pertencentes a partidos de oposição ao arco de aliança do governo Dilma. O mesmo se pode dizer em relação à sociedade, representada, basicamente, por agentes do campo cultural. Os lugares de fala são bastante distintos no que se refere à situação geográfica, pois oriundos de todas as regiões do país. Nesse sentido, pode-se afirmar, recorrendo aos termos de Ernesto Laclau e Chantal Mouffe (2010), que se dá em torno do SNC uma regularidade discursiva a partir de uma dispersão de posições de sujeito.

Vejamos alguns desses discursos, com alguns destaques em itálico feitos por mim. Comecemos por aqueles que ex- põem claramente a virtude do diálogo entre poder público e sociedade civil para a construção de políticas culturais.

Para o secretário de Estado da Cultura de Alagoas, Osvaldo Viégas, a III Conferência Estadual é "mais um momento de interlocução entre poder público e sociedade civil no intuito de estabelecer diretrizes para o desenvolvimento da cultura em Alagoas"6. Assis Brasil, secretário de Estado da Cultura do Rio Grande do Sul, ao fazer referências ao sistema estadual de cultura, expõe seu entendimento de que "instrumentos políticos, quando legislados pela vontade comum e sistematizados, são garantidores da plenitude da vida social, do exercício da democracia e da plena participação cidadã". Seu Secretário adjunto, Jéferson Assumção, radicaliza tal entendimento e afirma que é na participação que "qualificamos o que pensamos" e por conta dela "já estamos praticando o Sistema Estadual de Cultura"8. Ou seja, a participação é o próprio elemento definidor do sistema de cultura.

Para Eliane Martins Silva, secretária de Estado dos Esportes, da Cultura e do Lazer de Rondônia, a Conferência Estadual de Cultura se configura como "um momento impar na história da Cultura do Estado, por se tratar de uma ação com o objetivo de se discutir e traçar as diretrizes do Plano Estadual de Cultura de Rondônia numa articulação e cooperação em poder público e sociedade civil"'.

Tal participação é entendida, por alguns agentes, como momento de confronto de opiniões distintas, ou mesmo contraditórias. Francis Mary, presidenta da Fundação de Cultura Elias Mansour do Acre, avalia que a $3^{a}$ Conferência Estadual de Cultura "foi um processo democrático de embates de ideias, que contribui para o aprimoramento das políticas culturais a nível estadual e nacional"10. A secretária de Estado da Cultura de Sergipe, Eloísa 
Galdino, defende que "as conferências municipais visam a mobilização das comunidades para o debate e a proposição de políticas de Cultura junto a representantes do poder publico". Na sua avaliação, "através do evento e de outras ações, favorecemos a participação intensa e coletiva dos agentes de cultura, com base em uma visão diferenciada sobre como construir políticas públicas para esta área"11.

Mas destes embates sai uma deliberação consensual, o que reforça a própria democracia. Esta é a avaliação, por exemplo, da diretora de projetos e difusão cultural da Secretaria de Estado da Cultura de Sergipe, Celiene Lima: "O principal motivo de reunir nas conferências, gestores e a população, o que inclui os agentes culturais, é o de promover deliberações que favoreçam a consolidação democrática e participativa de uma política cultural nos municípios, no Estado e no país"12.

No Pará, o presidente da Fundação Tancredo Neves, Nilson Chaves, comentou sobre a III Conferência Estadual de Cultura: "Temos aqui uma representatividade maravilhosa de pessoas que acreditam que tudo pode mudar. Juntas, essas pessoas podem se fortalecer e aprimorar o conceito de cultura em nível nacional"13. No âmbito legislativo, o deputado Edmilson Rodrigues (PSOL/ PA) defendeu, durante a referida Conferência, a implantação do Sistema Nacional de Cultura, pois faz-se necessário "construir coletivamente uma política de cultura de estado - que contemple todos os setores da sociedade, municípios de todas as regiões, respeitando a diversidade regional - porque os governos mudam, mas a cultura do povo fica e tem que ser fortalecida" ${ }^{14}$.

A secretária de Cultura do Maranhão, Olga Simão, falando dos mais de 120 municípios que realizaram as conferências municipais, avalia que "impõe-se às instituições e à sociedade civil o dever de caminhar juntos para que o fazer cultu- ral seja também o esforço de criar condições, facilitar e assegurar a manutenção dos valores que convivemos, enfim, de pensar uma política de Estado para a cultura com a participação de todos".

Outro entendimento, vinculado aos que já destaquei, é o de fortalecimento da sociedade com a realização das conferências e a criação do sistema. Para Marcos Garcia, delegado na Conferência Estadual e eleito pelo município maranhense de Raposa, representando a área da música, o encontro traz ganhos para toda a sociedade: "Essa é uma iniciativa que incentiva a sociedade civil a participar ativamente, fortalecendo os grupos organizados e os fóruns de discussão"15. Na III Conferência Estadual da Cultura do Paraná, Laura Chaves, de Maringá, uma das delegadas eleitas da área governamental, avalia que "as sugestões do grupo realmente refletem um pensamento coletivo, tanto estadual quanto nacional. O equilíbrio de propostas gera um aprendizado para todos os envolvidos e prova que a gente consegue pensar a cultura enquanto direito". Para Érico Massoli, de Curitiba, também um dos delegados eleitos, "a conferência de cultura (...) serviu para um amadurecimento da sociedade civil"16.

Na abertura da Conferência de Cultura do Distrito Federal, o secretário de Cultura Hamilton Pereira defendeu que o evento "retratará o processo de indignação e levante das massas populares", pois "não podemos esquecer que no mês de julho, as ruas foram invadidas pelas reivindicações de todos os cantos do país e este espírito está e deve ser levado para a CNC para a construção de uma política pública eficaz para a classe cultural do DF e do Brasil"17. Ainda sobre o DF, o jornalista e presidente do Conselho de Cultura, Romário Schettino, pergunta-se: "para que um sistema cultural no DF?". Entre os elementos que traz para sua resposta, a participação da sociedade é um dos mais for- 
tes argumentos a favor do sistema, o que "não é pouca coisa", pois essa "mudança de paradigmas exige de todos nós mais dedicação e compreensão política para o momento histórico em que vivemos"18.

Em Tocantins, o diretor de cultura da Secretaria Estadual de Educação, Célio Pedreira, destacou que "a política cultural deve abranger o conjunto múltiplo das formas de pensamento, sensibilidade e expressão dos vários segmentos da população. Discutimos [na Conferência Estadual de Cultura] as necessidades do segmento, recebemos informações que vão nortear as ações do poder publico". Para a delegada da cidade de Muricilândia (TO), Iraci Martins Ferreira, "não existe política pública sem participação popular. Esse é um momento de suma importância, onde é aberto o espaço para o diálogo, a troca de ideias, com a finalidade de fortalecer a cultura do nosso estado"19. No município de São José, Santa Catarina, o superintendente adjunto da Fundação Municipal de Cultura e Turismo, Caê Martins, entende que o Sistema é "fruto de um anseio participativo, debatido com a sociedade e é assim que desejamos que a cultura passe a ser gerida" 20 .

A secretária de Cultura de Minas Gerais, Eliane Parreiras disse acreditar que a conferência será um fórum privilegiado para identificar as "demandas, reivindicações e anseios da população, levando-se em consideração as peculiaridades e características regionais. Queremos fomentar o diálogo entre os diferentes representantes da cadeia da cultura no estado. Esse é um momento de reflexão e consolidação para chegarmos numa política pública de cultura abrangente e forte ${ }^{21}$.

O discurso pela participação tem um outro formato, que coaduna com os que acabamos de ver, que é o do reforço federativo no âmbito das políticas culturais, que será permitido pelo SNC. O secretário Assis Brasil situou: "Almejamos uma estratégia de atuação que nos possibilite chegar para além das populações urbanas de nossas grandes cidades, aos povos de todo este vasto território". Para a deputada Ana Affonso (PT/RS), "pela primeira vez na história estamos integrando todos os municípios ao estado e à união nesta organização sistemática e principalmente fortalecendo as culturas populares do estado"22. Como esclarece a secretária Eloísa Galdino, as decisões colhidas em cada evento serão levadas à etapa estadual, na perspectiva de favorecer o alcance dos objetivos já definidos, em especial, os que implicam na estruturação do Sistema e do Plano Estadual de Cultura. Ações que implicam na aquisição de inúmeros benefícios para as ações culturais a serem dinamizadas e cada vez mais aperfeiçoadas nas esferas municipal, estadual e nacional.

O secretário de Cultura de Laranjeiras, Sergipe, Irineu Fontes, ressalta "a cooperação de todos os envolvidos na etapa municipal, sejam agentes culturais, dirigentes e secretários, cujo resultado de tamanho empenho será ainda mais evidenciado nas Conferências Estadual e Nacional de Cultura"23.

Na avaliação do prefeito de Alcântara, Maranhão, Domingos Araquém, "temos que estar integrados com o Sistema Nacional da Cultura, e a realização desse encontro propicia aos gestores públicos conhecer o sistema e incorporar nos municípios ações para desenvolver a cultura, produzindo também emprego e renda para a população"24.

Segundo o secretário de Cultura de Divinópolis, Minas Gerais, Bernardo Rodrigues, "sem uma revisão do pacto federativo, com distribuição mais justa das receitas entre os entes federados, caminharemos pouco no sentido de fortalecer as ações não só da área da cultura, mas as políticas públicas municipais como um todo", argumenta. De acordo com Rodrigues, 
precisamos de mais investimentos que venham do governo federal e isso depende de um melhor repasse de recursos. A ideia do Sistema Nacional de Cultura é exatamente com esse propósito, pois não adianta criar um sistema de cultura, sem criar um percentual mínimo de investimento para cada ente federado e não ocorrer uma revisão do pacto federativo. Vamos levar para Brasília as nossas reivindicações e tentar fazer com que o Sistema Nacional de Cultura saia, finalmente, do papel e assim tenhamos mais condições de investimentos e melhorias nos municípios ${ }^{25}$.

Para o secretário de Estado da Cultura da Paraíba, Chico César, a Conferência Estadual foi positiva

primeiro por aproximar Governo e agentes culturais, poder público e sociedade civil. Mas também, pelo fato de ter sido realizada no sertão paraibano, na cidade de Sousa, conseguiu aproximar as diversas regiões: Sertão, Cariri, Brejo, Borborema e Litoral. Foi perceptível a valorização do interior do Estado, inclusive na escolha dos delegados que vão a Brasília no final de novembro como representação da cultura paraibana ${ }^{26}$.

O presidente da Fundação Cultural de Itaboraí, Rio de Janeiro, Cláudio Rogério Dutra, defende que a delegação do município "tem por objetivo principal não só buscar apoio para Itaboraí, como também para os municípios circunvizinhos"27.

Contudo, a lógica pode ser a de uma postura de disputa ou pelo menos de reivindicação da parcela que cabe a cada estado ou município, revelando os traços de uma cultura política ainda pouco republicana e federativa (CUNHA FILHO; RIBEIRO, 2013), em especial no campo cultural que historicamente, como foi visto na parte introdutória, foi pouco contemplado com políticas públicas sistêmicas e duradouras. O secretário de Estado da Cultura do Paraná, Paulino Viapiana, por exemplo, defende que

a conferência deve funcionar como a representação de um pensamento coletivo. Sairemos daqui fortalecidos para uma conferência nacional. É o momento de o nosso Estado unir forças e buscar em Brasília a participação que nos é devida por conta da importância econômica e cultural que o Paraná tem ${ }^{28}$.

Já o vereador $\mathrm{Cb}$. Anísio (PDT/MG) de Manhuaçu, Minas Gerais, revela que "os municípios maiores tentaram articular para desbancar os municípios menores, a fim de não deixarem participar de uma conferência como essa. Agora, a nossa proposta é levar para Brasília as propostas e, lutarmos para que a nossa região seja beneficiada"29.

\section{Considerações conclusivas: hegemonização em torno do Sistema Nacional de Cultura}

A partir dos discursos analisados acima, parece-me plausível propor a tese de que houve em torno do Sistema Nacional de Cultura um processo de hegemonização, ou seja, de construção de uma ampla identidade social com essa política cultural, tendo o Ministério da Cultura como agente principal na articulação das diferentes posições de sujeito.

Como observam Laclau e Mouffe, a hegemonia opera em um movimento estratégico complexo de negociação entre discursos. Trata-se de uma operação dominada pela categoria de articulação que pressupõe, precisamente, especificar a identidade dos elementos articulados: "Se a articulação é uma prática e não o nome de um complexo relacional dado", lembram os autores, isto "implica alguma forma de presença separada dos elementos que a prática articula ou recompõe" (LACLAU; MOUFFE, 2001, p.129). 
$\mathrm{Na}$ lógica articulatória posta em ação pela hegemonização, a organização dos fragmentos discursivos é contingente e externa a eles e não uma totalidade subjacente ou suturada. Como observam, "um conjunto de elementos aparecem fragmentados ou dispersos somente desde o ponto de vista de um discurso que postule a unidade entre os mesmos" (LACLAU; MOUFFE, 2001, p. 132-133), de modo que não é possível falar de fragmentação de fora da formação discursiva, entendida aqui como uma prática articulatória que constitui e organiza as relações sociais.

O que se depreende da análise é que os esforços construídos paulatinamente pelo MinC, com avanços e retrocessos, em torno do projeto do Sistema Nacional de Cultura desde 2003, tornou-o uma proposta consensual no meio político e no campo cultural brasileiros. Há, certamente, uma pré-disposição a tal consenso, posto que a criação de sistemas federativos de políticas públicas já se deu em outros setores, não apenas na saúde com o SUS, mas também na educação, na assistência social, no meio ambiente etc. $E$ no que se refere à participação da sociedade, esta também não é novidade, pois instrumentos de governança, entendida aqui como interação entre o poder público e a sociedade civil com intuito de garantir participação popular, controle, transparência e eficácia das políticas públicas (BOSCHI, 1999), também vêm sendo implementados de forma crescente em outros campos, incluindo o cultural $^{30}$, desde a Constituição de 1988.

No entanto, esse contexto prévio foi reforçado pelas ações do MinC com vistas a articular apoio ao SNC. Nesse sentido, foi criada, com a reforma do MinC em 2003, a Secretaria de Articulação Institucional e de Difusão Cultural, atual Secretaria de Articulação Institucional (SAI), cujo objetivo central é o de construir o Sistema. No sítio eletrônico do MinC, pode-se ler a seguinte definição da SAI: "promove a articulação federativa por meio do Sistema Nacional de Cultura, e cuida da integração de políticas, programas, projetos e ações culturais executadas pela União, Estados, Distrito Federal e Municípios, com a participação da sociedade" 31 .

Do grupo de trabalho instituído pela Secretaria, surgiu a Proposta de Emenda Constitucional (PEC) No 416 que instituiu o SNC e foi apresentada ao Congresso Nacional em 2005. Nesse mesmo ano, realizou-se a I Conferência Nacional de Cultura (CNC), que foi antecedida por uma ampla mobilização nacional, resultado das conferências municipais e estaduais. A CNC definiu como uma de suas prioridades a implementação do SNC.

Também em 2005 foram criados o Sistema Federal de Cultura e o Conselho Nacional de Política Cultural, bem como implementada a campanha de Assinatura do Protocolo de Intenções para implantação do SNC que resultou na adesão de 21 estados e 1.967 municípios. No ano seguinte, motivados pelo Protocolo, o MinC realizou o $\mathrm{Ci}$ clo de Oficinas do Sistema Nacional de Cultura (BRASIL, 2006) e o Governo do Ceará criou o primeiro Sistema Estadual de Cultura (BARBALHO; HOLANDA, 2013). Em 2007, foi a vez de criação do primeiro Sistema Municipal de Cultura, no caso, o de Rio Branco, Acre (BARROS; MACHADO, 2013).

Em 2009, o Conselho Nacional de Política Cultural aprovou o documento "Proposta de Estruturação, Institucionalização e Implementação do Sistema Nacional de Cultura". Para divulgar a proposta do Sistema, o MinC realiza, no mesmo ano, os Seminários do SNC em 24 estados, totalizando a participação de 4.577 gestores e conselheiros de cultura de 2.323 municípios (BRASIL, 2011a).

Entre 2009 e 2010, a SAl elabora o Programa de Formação de Gestores Culturais, cujo Curso Piloto de Gestão Cultural ocorre na Bahia, e o mapeamento das insti- 
tuições públicas e privadas que promovem cursos de formação cultura| ${ }^{32}$. Em 2010, a II Conferência Nacional de Cultura, que foi antecedida por Conferências de Cultura em 3.216 Municípios, 26 estados e no Distrito Federal, referenda o SNC, elegendo-o prioridade principal. Tanto que o Plano Nacional de Cultura (PNC), que resulta das Conferências e que, aprovado pelo Congresso Nacional, foi sancionado pelo Presidente Lula na forma da Lei no 12.343 de 2010, estabelece como meta 1 o "Sistema Nacional de Cultura institucionalizado e implementado, com $100 \%$ das Unidades da Federação (UF) e $60 \%$ dos municípios com sistemas de cultura institucionalizados e implementados" (BRASIL, 2011b, p. 11).

Entre 2011 e 2012, foram elaborados e distribuídos no país o documento intitulado "Estruturação, Institucionalização e Implementação do SNC" e as cartilhas "Guia de Orientações do SNC (Perguntas e Respostas) - para Municípios" e "Guia de Orientações do SNC (Perguntas e Respostas) - para os Estados“.

Em 2011, a Comissão do Fundo Nacional de Cultura, a partir de diretriz do Conselho Nacional de Política Cultural, deliberou destinar para o ano de 2012, 40\% do valor global do orçamento do FNC para transferência aos entes federados que aderiram ao SNC. No ano seguinte, foi aprovado e promulgado pelo Congresso Nacional a Emenda Constitucional $n^{\circ} 71 / 2012$ que introduz o Sistema Nacional de Cultura na Constituição Federal. A partir de então, a SAI vem assessorando a elaboração de planos estaduais e municipais de cultura em todo o país, bem como recebendo adesões ao Sistema, cujo processo teve na III Conferência Nacional de Cultura não seu momento de finalização, mas, até o momento, o mais simbólico desse esforço de institucionalização das políticas culturais no Brasil.

Nesse sentido, é que o MinC/SAI implementou uma ampla agenda nacional em torno do SNC, garantindo para o referido Sistema o apoio de amplos setores dos campos politico e cultural, algo que não ocorreu, por exemplo, quando da tentativa de criação da Agência Nacional de Cinema e do Audiovisual (ANCINAV), inviabilizada por agentes desse subcampo (o do audiovisual), em especial os empresários do setor, contrários ao tipo de regulação que a ANCINAV iria por em prática.

\section{Bibliografia}

ARAÚJO, Anarda Pinheiro; MARTIN, Natália Luiza Alves; CÂNDIDO, Nathalie Carvalho; OSÓRIO, Lícia Maria Teixeira. Sistema Nacional de Cultura (SNC): um reflexo da estrutura do Sistema Unico de Saúde (SUS)? In: VI ENCONTRO DE ESTUDOS MULTIDISCIPLINARES EM CULTURA - ENECULT, 2011. Anais... Salvador: UFBA, 2011.

BARBALHO, Alexandre. Política cultural e Orçamento Participativo: ou as possibilidades da democracia cultural na cidade contemporânea. Políticas Culturais em Revista. Salvador: v. 5, p. 156-169, 2012.

. Conselhos de cultura e democracia: desafios contemporâneos. In: RUBIM, Albino; FERNANDES, Taiane; RUBIM, luri. (org.). Políticas culturais, democracia e conselhos de cultura. Salvador: UFBA, 2010. p. 237-254.

O Orçamento Participativo e os dados da Munic Cultura 2006: o caso de Fortaleza. In: CALABRE, Lia (ORG.). Políticas culturais: reflexões e ações. São Paulo: Itaú Cultural, 2009. p. 91-104.

; RUBIM, Albino (org.). Políticas culturais no Brasil. Salvador: UFBA, 2007.

COSTA, Leonardo. Formação em organização da cultura: a situação latino-americana. Pragmatizes. Niterói: ano 2, n. 2, p. 125-149, 2012.

BARROS, José Márcio; CALABRE, Lia (org.). Federalismo e políticas culturais no Brasil. Salvador: UFBA, 2013. 
; HOLANDA, Jocastra. O partido da cultura: política cultural no Ceará na Era Lula. In: BARBALHO, Alexandre; BARROS, José Márcio; CALABRE, Lia (org.). Federalismo e políticas culturais no Brasil. Salvador: UFBA, 2013. p. 115-130.

BARROS José Márcio; MACHADO, F. B. O Acre e o Brasil: continuidades e singularidades nas políticas culturais. In: BARBALHO, Alexandre; BARROS, José Márcio; CALABRE, Lia (org.). Federalismo e políticas culturais no Brasil. Salvador: UFBA, 2013. p. 43-74.

BOSCHI, R. Descentralização, clientelismo e capital social na governança urbana: Comparando Belo Horizonte e Salvador. Dados. São Paulo: v. 42, n. 4, 1999.

Brasil. Ministério da Cultura. Oficinas do Sistema Nacional de Cultura. Brasília: Ministério da Cultura, 2006.

Estruturação, Institucionalização e Implementação do Sistema Nacional de Cultura. Brasília: Ministério da Cultura, 2011a.

Metas do Plano Nacional de Cultura. Brasília: Ministério da Cultura, 2011b.

. III Conferência Nacional de Cultura. Texto-base. Brasília: Ministério da Cultura, 2013.

CUNHA FILHO, Francisco Humberto; RIBEIRO, Sabrina Florêncio. Federalismo brasileiro: significados para a cultura. In: BARBALHO, Alexandre; BARROS, José Márcio; CALABRE, Lia (org.). Federalismo e políticas culturais no Brasil. Salvador: UFBA, 2013. p. 13-41.

FALLETI, Tulia G. Infiltrando o Estado: a evolução da reforma da saúde no Brasil, 1964 - 1988. Estudos de sociologia. Araraquara: v.15, n.29, 2010, p.345-368.

LACLAU, Ernesto; MOUFFE, Chantal. Hegemonía y estrategia socialista. Hacia una radicalización de la democracia. Buenos Aires: Fondo de Cultura Económica, 2010.

MEMICUCCI, Telma Maria Gonçalves; BRASIL, Flávia de Paula Duque. Construção de agendas e inovações institucionais: análise comparativa da reforma sanitária e da reforma urbana. Estudos de sociologia. Araraquara: v.15, n.29, 2010, p.3469-396.
RUBIM, Albino. As Políticas Culturais e o Governo Lula. São Paulo: Fundação Perseu Abramo, 2011.

(org.). Políticas Culturais no Governo Lula. Salvador: UFBA, 2010.

SANTOS, Wanderley Guilherme. Cidadania e justiça. Rio de Janeiro: Campus, 1979.

1 Professor dos PPGs em Políticas Públicas da UECE e em Comunicação da UFC. Contato: alexandrealmeidabarbalho@gmail.com

2 A esse respeito ver, entre outros, FALLETI (2010) e MEMICUCCI; BRASIL (2010).

3 O SUS é explicitamente utilizado como parâmetro para o SNC, como comprova a seguinte passagem retirada do documento "Estruturação, Institucionalização e Implementação do SNC": "A inspiração para o SNC veio dos resultados alcançados por outros sistemas de articulação de políticas públicas instituídos no Brasil, particularmente o Sistema Único de Saúde (SUS). A experiência do SUS mostrou que o estabelecimento de princípios e diretrizes comuns, a divisão de atribuições e responsabilidades entre os entes da Federação, a montagem de um esquema de repasse de recursos e a criação de instâncias de controle social asseguram maior efetividade e continuidade das políticas públicas" (BRASIL, 2011a, p. 40). Para uma análise comparativa entre o SUS e o SNC ver ARAÚJO et al (2010).

4 Entrevista com Roberto Peixe concedida ao autor. Salvador, 13.set.2013.

5 O que equivale a $37,2 \%$ dos municípios brasileiros. Dados atualizados pelo MinC em 19.11.2013 e disponível em http://www.cultura.gov.br/documents/10907/1030302/ Quantitativo+de+Munic\%C3\%ADpios+e+Estados+com +Acordo.pdf/82735882-d103-4953-bdba-c031d0e9f008. Acesso em 02.dez.2013.

6 Disponível em http://primeiraedicao.com.br/noticia/2013/08/30/iv-conferencia-estadual-de-cultura-e-aberta-e-maceio . Acesso em 06.nov.2013.

7 Disponível em http://www.rs.gov.br/noticias/1/115988/ Avancos-das-politicas-publicas-pauta-a-abertura-da-4a-Conferencia-Estadual-de-Cultura. Acesso em 14.nov.13

8 Disponível em http://www.cultura.gov.br/banner-3/-/ asset_publisher/axCZZwQo8xW6/content/conferencias-nos-estados/10883. Acesso em 14.nov.13 
9 Disponível em http://www.cultura.gov.br/por-dentro-do-ministerio/-/asset_publisher/dhdgdV8fiG9W/content/conferencias-em-mais-sete-estados/10883?red irect=http $\% 3 \mathrm{~A} \% 2 \mathrm{~F} \% 2 \mathrm{Fwww}$.cultura.gov. br\%2Fpor-dentro-do-ministerio\%3Fp_p_id\%3D101_INSTANCE_dhdgdV8fiG9W\%26p_p_lifecycle\%3D0\%26p_p_ state\%3Dnormal\%26p_p_mode\%3Dview\%26p_p_col_ id\%3Dcolumn-1\%26p_p_col_count\%3D1. Acesso em 14.nov.13

10 Disponível em http://www.cultura.gov.br/por-dentro-do-ministerio/-/asset_publisher/dhdgdV8fiG9W/content/ conferencias-no-norte-e-nordeste/10883. Acesso em 14.nov. 13

11 Disponível em http://www.cultura.gov.br/banner-3/-/ asset_publisher/axCZZwQo8xW6/content/conferencias-nos-estados/10883. Acesso em 14.nov.13

12 Disponível em http://www.brasil247.com/pt/247/ sergipe247/114363/Conferência-Estadual-de-Cultura-ocorre-nos-dias-26-e-27-de-setembro.htm. Acesso em 06.nov.2013.

13 Disponível em http://www.cultura.gov.br/por-dentro-do-ministerio/-/asset_publisher/dhdgdV8fiG9W/content/ conferencias-no-norte-e-nordeste/10883. Acesso em 14.nov.13

14 Disponível em http://www.edmilsonbritorodrigues. com.br/edmilson-defende-implantacao-do-sistema-nacional-de-cultura/. Acesso em 06.nov.2013.

15 Disponível em http://oprogressonet.com/noticiario/14804/regional/2013/9/13/conferencia-estadual-de-cultura-debate-politica-de-estado-para-o-setor/. Acesso em 14.nov.13

16 Disponível em http://www.aen.pr.gov.br/modules/ noticias/article. php? storyid=76828\&tit=Conferencia-Estadual-da-Cultura-elege-28-delegados-para-etapa-nacional. Acesso em 14.nov.13

17 Disponível em http://www.cultura.gov.br/por-dentro-do-ministerio/-/asset_publisher/dhdgdV8fiG9W/ content/conferencias-em-mais-sete-estados/10883?r edirect=http $\% 3 \mathrm{~A} \% 2 \mathrm{~F} \% 2 \mathrm{Fwww}$.cultura.gov.br\%2Fpor-dentro-do-ministerio\%3Fp_p_id\%3D101_INSTANCE_dhdgdV8fiG9W\%26p_p_lifecycle\%3D0\%26p_p_ state\%3Dnormal\%26p_p_mode\%3Dview\%26p_p_col_ id\%3Dcolumn-1\%26p_p_col_count\%3D1. Acesso em 14.nov.13

18 Disponível em http://clippingmp.planejamento.gov. br/cadastros/noticias/2013/10/19/para-que-um-sistema-cultural-no-df. Acesso em 14.nov.13

19 Disponível em http://www.cultura.gov.br/por-dentro-do-ministerio/-/asset_publisher/dhdgdV8fiG9W/ content/conferencias-em-mais-sete-estados/10883?r edirect=http $\% 3 \mathrm{~A} \% 2 \mathrm{~F} \% 2 \mathrm{Fwww}$.cultura.gov.br\%2Fpor-dentro-do-ministerio\%3Fp_p_id\%3D101_INSTAN-
CE_dhdgdV8fiG9W\%26p_p_lifecycle\%3D0\%26p_p_ state\%3Dnormal\%26p_p_mode\%3Dview\%26p_p_col_ id\%3Dcolumn-1\%26p_p_col_count\%3D1. Acesso em 14.nov.13

20 Disponível em http://www.pmsj.sc.gov.br/2013/10/ prefeita-adeliana-dal-pont-sanciona-a-lei-que-cria-o-sistema-municipal-de-cultura/?utm_source=rss\&utm medium=rss\&utm_campaign=prefeita-adeliana-dal-pont-sanciona-a-lei-que-cria-o-sistema-municipal-de-cultura. Acesso em 14.nov.13

21 Disponível em http://www.otempo.com.br/capa/ minas-adere-ao-sistema-nacional-de-cultura-1.719330. Acesso em 15.nov.13

22 Disponível em http://www.cultura.rs.gov.br/ v2/2013/09/governador-sanciona-lei-do-sistema-estadual-de-cultura/. Acesso em 06.nov.2013.

23 Disponível em http://www.brasil247.com/pt/247/ sergipe247/114363/Conferência-Estadual-de-Cultura-ocorre-nos-dias-26-e-27-de-setembro.htm. Acesso em 25.nov.2013.

24 Disponível em http://oprogressonet.com/noticiario/14804/regional/2013/9/13/conferencia-estadual-de-cultura-debate-politica-de-estado-para-o-setor/. Acesso em 14.nov.2013.

25 Disponível em http://www.divinopolis.mg.gov.br/portal/noticia. .php?id=10197. Acesso em 27.nov.2013

26 Disponível em http://www.paraiba.pb.gov.br/77167/ conferencia-estadual-apresenta-resultados-positivos-para-o-setor-de-cultura.html. Acesso em 25.nov.2013

27 Disponível em http://www.prefeituraitaborai. com/4177/itaborai-tera-tres-delegados-na-conferencia-nacional-de-cultura/. Acesso em 27.nov.2013

28 Disponível em http://www.oparana.com.br/variedades/cascavel-conquista-tres-vagas-na-conferencia-nacional-de-cultura-39213/. Acesso em 14.nov.13

29 Disponível em http://www.portalcaparao.com.br/lernoticia/12758/manhuacu-tera-representantes-na-conferencia-de-cultura. Acesso em 25.nov.2013

30 São os casos, por exemplo, dos conselhos de cultura e da deliberação de recursos para a cultura por meio do Orçamento Participativo. A esse respeito ver BARBALHO (2012; 2010; 2009).

31 Disponível em http://www.cultura.gov.br/secretarias1. Acesso em 04.dez.2013.

32 A esse respeito ver BARBALHO; RUBIM; COSTA (2012). 